\title{
Intangibles: enhancing access to cities' cultural heritage through interpretation
}

\author{
Nicole Mitsche, Franziska Vogt, Dan Knox, I. Cooper, Patrizia Lombardi and Daniela Ciaffi
}

\author{
Nicole Mitsche is based at \\ the University of \\ Sunderland, Sunderland, \\ UK. Franziska Vogt is \\ based at the University of \\ Westminster, London, UK. \\ Dan Knox is based at \\ Liverpool John Moores \\ University, Liverpool, UK. \\ I. Cooper is based at \\ Eclipse Research, \\ Cambridge, UK. \\ Patrizia Lombardi and \\ Daniela Ciaffi are based at \\ the Dipartimento Casa \\ Città, Politechnico Turino, \\ Turin, Italy.
}

This work was co-funded by the European Union's 6th Framework Programme (ISAAC IST-2006-035130). The results of this report are available in an extended form on the project's website (see www.isaacproject.eu). The authors thank the representatives in the partner cities - Egbert Wolf (City of Amsterdam), Susanne Heydenreich (City of Leipzig) and Paulo Dallorso (City of Genoa) - for their ongoing collaboration, active contributions, discussions and their hospitality in facilitating the workshops and all other colleagues of the ISAAC team for their valuable contributions.

\begin{abstract}
Purpose - The purpose of this paper is to utilise commodification for the conservation and promotion of cultural heritage in cities by developing interpretative strategies, specifically enabling access to intangible cultural heritage through its tangible parts.
\end{abstract}

Design/methodology/approach - In total, three case studies were conducted in the cities of Amsterdam, Genoa and Leipzig, through a workshop cycle with destination and local tourism stakeholders and citizen representatives, to develop interpretative strategies for the cities.

Findings - The paper identifies tangible and intangible cultural heritage of the three cities, and integrates them into stories and outlines the development of an interpretative strategy for destinations independent from, but aligned with, the current marketing and positioning strategy development level.

Research limitations/implications - Future research should examine the integration process of interpretative strategies and heritage interpretation of cultural heritage in marketing strategies, and in particular focus on the intangible aspects.

Originality/value - The article integrates and highlights the value of intangible cultural heritage and interpretation of cultural heritage in general for marketing purposes through the development of an interpretative strategy improving access to destinations' cultural heritage supporting destination management. The article adds to the research discussion of the commodification of cultural heritage.

Keywords The Netherlands, Italy, Germany, Cities, Heritage, Culture, Intangible cultural heritage, Heritage interpretation, Destination marketing, Commodification

Paper type Research paper

\section{Introduction}

The importance of cultural heritage is recognised by many for tourism experiences, motivations and behaviour (Nyapaune et al., 2006; Timothy and Boyd, 2003; Prentice and Duncan, 1994) and in a similar way for societal and community well-being, and sustainable urban development (Tweed and Sutherland, 2007). Destinations use this value of heritage by directly or indirectly commodifying heritage in their tourism marketing strategies (Ashworth et al., 2007).

In particular for destination positioning, and brand and image building, cultural heritage is one of the factors that enable destinations to create unique images and imaginations in people's minds. Destinations have to work hard to keep a competitive advantage in the tourism market, differentiating and customising their products and services (McCabe, 2009; Ritchie and Crouch, 2000) in relation to their competitors. In this process, positioning relies on both the tangible (physical) and intangible (immaterial) elements of a destination's cultural heritage. Interpretation of cultural heritage is not only a gateway of understanding the cultural heritage itself, but also places the cultural heritage in the context of the destination and its people.

Developing an interpretative strategy through the evaluation of a destination's cultural heritage, exploring not only its physical representation but also its intangible elements by 
destination management, its cultural heritage stakeholders and citizen representatives, does not only enable destination to unlock its unique potential but also creates a sense of place that local communities can identify and relate to.

This paper presents research that has been conducted as part of the ISAAC project (European Union's 6th Framework Programme ISAAC IST-2006-035130; see www.isaacproject.eu). The project aims to promote cultural heritage tourism through a novel information communication technology (ICT) environment, providing integrated and user-friendly tourism e-services that facilitate wide virtual access to European cultural heritage assets. This paper focuses on the identification of cultural heritage, in particular its intangible aspects and stories worthwhile to be told, within a destination. It outlines the development of an interpretative strategy independent from, but aligned with, the current marketing and positioning strategy development level on the examples of three cities i.e. Amsterdam (The Netherlands), Genoa (Italy) and Leipzig (Germany).

\section{Destination positioning}

Destination positioning presents a form of market communication, and used in tourism marketing it enables tourist destinations to enhance their attractiveness and competitiveness through the development of a unique distinctive position compared to their competitors (McCabe, 2009; World Trade Organization, 2006; Selby, 2004; Buhalis, 2000). This position is necessary to enable potential visitors to picture and visualise the destination in mind as a distinctive place.

Ideally this evokes images of a destination that is different from its competitors, which can be based on the differentiation of the offer, the prices, a specialised focus on offering, or a combination of them (Chacko, 1997; Kotler et al., 2006) and also mirror the character and personality of the destination (Sainaghi, 2006). A successful positioning strategy has the further advantage of enabling the destination to increase its market share, face rising competition, enhance competitiveness or even gain a competitive edge (Buhalis, 2000; Go and Govers, 2000). For a positioning strategy to be effective Crompton et al. (1992) suggest that the destination attributes that are perceived as important by the target market should be identified first. Unique selling points (USPs) are components of a destination that are unique when compared to its competitors and provide it with an exceptional appeal in relation to market needs. Thus, they are crucial in order to differentiate a destination from its competitors. Kotler et al. (2006) suggest that USPs can consist of a single factor or a combination of several factors (e.g. best quality, best service, lowest price). However, Prentice (2006) argues that effective USPs are redefined by consumers but may be proposed by destinations. Thus, they should not be assumed, but instead their importance has to be identified and then represented back to consumers. Furthermore, Prentice (2006) enhanced USPs by the tourist's lived experiences and cultural familiarity with a destination.

Physical (tangible) qualities and attributes, and as part of this (built and natural) heritage, are main basis for most positioning strategies (McCabe, 2009). Cultural heritage is firstly thought of in its physical space, although cultural heritage extends beyond this. In a sense, not only the fact of the existence but also the particular use of the sites (can) make them heritage sites. Heritage can also be the experience in itself, which makes apparent how important memory, remembering and performance are (Smith, 2006).

The physical and material aspects of a destination, called tangibles, include fortified structures, urban developments, monuments and memorials, religious buildings including churches and especially monasteries, buildings associated with production or manufacture (farms, factories, etc.), government or civic buildings, villages, cultural landscapes, and manufactured objects in their context. The intangible (immaterial) qualities of a destination include such things as practices, representations, expressions, knowledge, skills, legends, language, tradition, religion, folklore, music and dance, handicrafts, etc. (Copeland and Delmaire, 2004; UNESCO, 1979). The challenge here is to make use of the intangible aspects. As the tourism product is made up largely of both elements, which are sometimes difficult to differentiate, destinations are marketing the intangibles with reference to tangible 
evidence, which is referred to as "tangibilising the intangible" (Black, 2005, Chacko, 1997) - creating an amalgam of tangibles and intangibles. Destinations are not only about the tangible and intangible components of cultural heritage, but also the meaning placed upon them and the representations created from them. This adds either cultural or financial value, and explains why they have been selected (Ashworth et al., 2007). Destination positioning is often expressed through branding and a tool for image creation. Marketing destinations through storytelling is likely to build favourable consumer-brand relationships (Woodside et al., 2008). Developments in particular in place branding illustrate that the intangibles and storytelling are essential for destinations, and that adding value through meaning enables the creation of a sense of place and identity for residents and tourists alike. Auckland (New Zealand) is an example that highlights this necessity, where stories and what the city is all about are the main content to enable the creation of a place identity and brand (Gnoth, 2008).

\section{Heritage interpretation}

Heritage interpretation is about transmitting appreciation or enthusiasm for a place that is thought to be special to people (Carter, 2001), and is applied to explain the importance of a place to its visitors (Timothy and Boyd, 2003). According to Herbert (1989, p. 191), the role of interpretation is "to make people more aware of the places they visit, to provide knowledge which increases their understanding and to promote interest which leads to greater enjoyment and perhaps responsibility". Interpretation is also a communication instrument to reveal the meaning behind the heritage and the given information by using objects, direct experience and instructive media (Tilden, 1957) or an activity used to present a message, or to facilitate an experience within attractions that visitors might not be able to experience without it (Prentice and Cunnell, 1997).

One dilemma that heritage interpretation faces is the tendency for people to believe what is presented to them in the name of authority - this is particularly true for messages emerging from public bodies (Hems, 2006). Interpretation has to be updated in response to new evidence and research in order to attempt to avoid such problems. Copeland (2006) alerts us to the need to remain aware of the distinctions between positivist and constructivist approaches to interpretation. Important in the context of interpretation is the recognition within constructivist approaches that meanings are always variable and individual, highly complex and contingent upon factors beyond either the message or the medium.

Similarly, accounts of existential models of authenticity tell us that authenticity effects are produced in the moment of the individual encounter and are as much about the consumer of an image as about the conditions and intentions of production (Knox, 2008; Wang, 1999). Copeland (2006) recognises that visitors bring ideas and assumptions to the site, and that these ready-made ideas need to become part of the interpretation, either challenging or confirming preconceived images (Hems, 2006). In this way, heritage venues only become special or unique places in relation to their broader context within cultural environments (Copeland, 2006). Additionally, through providing alternative ways of seeing the same object in different contexts, and enabling the visitor to unpeel the different layers of hidden meanings, new audiences can be attracted to cultural heritage sites and existing audiences sustained (Hems, 2006).

Interpretation plays an important role in experiencing places and combines both tangible and intangible aspects of the place. This experiential consumption enables destinations to brand and position themselves with unique selling points (USPS). To avoid becoming a substitutable or feel-alike destination, differentiation through USPs (Pike, 2009) can be used to enhance the lived experiences and cultural familiarity of a destination, as mentioned previously (Prentice, 2006). "Effective interpretation must involve audiences in hearing and telling past stories, it emphasises human experience and places it at the core of those stories" according to Hems (2006, p. 6). In particular, for destinations it means involving people who use the spaces - local people, communities, tourists and stakeholders. 


\section{What is an interpretative strategy?}

In general, interpretative strategies are mainly developed by attractions. Those interpretative strategies outline interpretation and interpretative media used within the attraction for their different visitor target groups to pursue key themes (and specific messages within those themes).

This interpretation utilises facts and embeds them into stories, which should enable a better understanding of the selected themes, and on the simplest level this should provide a more effective communication (Carter, 2001). Some places have already used interpretation on a geographical level. An example of a heritage interpretation policy is provided by the Heritage Council of New South Wales, Australia (Heritage Council of New South Wales, 2005). They aim to connect communities with their heritage in order to protect and sustain heritage values through interpretation. In more detail, this interpretation policy not only seeks to promote interpretation, but also acknowledges associations and meanings of heritage to the community and integrates heritage interpretation in environmental and cultural planning in state and local government organisations. Another example is HERIAN (2006), which supported 26 industrial communities of South East Wales (UK) in local interpretation plans.

Interpretative strategies (sometimes synonymously called interpretation strategies) deal with the bigger picture and act as guidance and a framework to ensure needs are met compared to the more often commonly used interpretation plan, which specifies planned interpretation in more detail. The Scottish Museums Council (2003b) outlined the content of an interpretative strategy:

- aims and objectives;

- mechanisms;

- timescales and priorities; and

- budgets and management.

The aims and objectives are centred around the questions "What?", "Why?" and "Who?", and it is apparent that these can easily be linked to destinations' positioning strategies and USPs. Table I contrasts and presents both perspectives, which where adapted from the literature (Black, 2005; Scottish Museums Council 2003a, b, c; Lord and Dexter, 2002; Carter, 2001) outlining a framework for aims and objectives of a destination-specific interpretative strategy.

Table I Interpretative strategy focus from attraction and destination perspective

What is special about a museum or site, and what is worthwhile interpreting from it:

- thematic areas

- meanings to reveal

- stories to tell

- what will interest visitors

- what else is being interpreted nearby and how does it relate to this

Why the need for interpretation? (attraction perspective)

- increase visitors' understanding of exhibits

- encourage conservation ethic

- provide fun and rewarding days out for families

- increase time people spent in museums, etc.

Who is the target?

To attract new visitors?

Improve provision for existing visitors?

Need for more research about visitors?

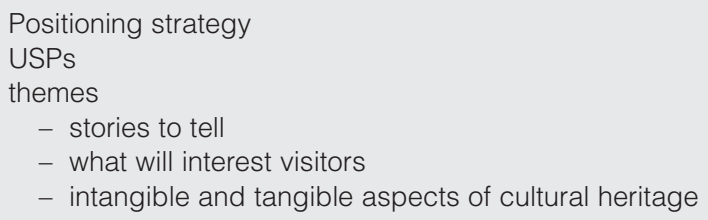

Target markets

Tourists (varied groups)

Residents

Community groups and groups of interests 
A similar approach can be adopted for the other steps developing a destination perspective viewpoint. The mechanism focuses on how to achieve those aims and objectives, while budget and management also includes the possible factors affecting their implementation.

This implies for destinations that interpretation can be utilised to enhance their positioning strategy (e.g. by the use of elements such as stories). Interpretation enables destinations to generate varied and more distinctive unique selling points through experiencing of or familiarity with the destination. An interpretative strategy uses the tangible and intangible aspects of a destination to provide key themes about that destination's offer to visitors. Thus, an interpretative strategy enhances a destination's positioning strategy by adding distinctiveness and flagging uniqueness.

\section{Method}

This research uses commodification for the conservation and promotion of cultural heritage in cities by developing interpretative strategies, specifically enabling access to intangible cultural heritage through its tangible parts. In particular this research aims to outline a generalised process for producing an interpretative strategy (as presented in Table I), which can be taken up by the project's partner cities (Amsterdam, Genoa and Leipzig) and other cities independent from, but aligned with, their current marketing and positioning strategy development level.

This should enable them to develop their own interpretative strategies that can then be taken forward, filled with more specific content and integrated in existing strategies. It was essential in this process to inform the destinations involved about the aims, and their expected inputs to the development of such an interpretative strategy in advance of holding workshops with them involving both destination and attraction managers, and keeping them integrated and as part of the process throughout.

A workshop cycle integrating destination managers, local attraction stakeholders and citizen representatives informs the interpretative strategies for each of the cities. Overall, three on-site workshops were held in each city. The first two workshops were held on two consecutive days in September/October 2007. The same workshop was given to two different audiences in each city. The first focused on the destinations' management operating at the strategic and institutional level with participants from marketing, branding and regeneration departments and institutions. The second workshop included participants from the cities' wider stakeholder groups (attraction managers and other tourism related businesses) and citizen groups and organisations. This division was made under the assumption that their perspectives on their cities were different ensuring to capture the different views, but also bringing these groups together in a stepwise process.

The content of the workshop aimed to introduce all of these types of stakeholders to the interpretative strategy, to provide background knowledge on destination positioning, branding, unique selling points and heritage interpretation, as well as to identify already unique aspects of the cities' cultural heritage based on background material provided by the city partners. The format of the workshop included short briefings about these themes, with subsequent break-out sessions where participants explored the themes through feedback worksheets and moderated discussion. In these sessions, the participants captured tangible components of a destination's cultural heritage as key and smaller attractions and their attributes, explored possible stories and experiences within the city landscapes and attractions and reflected on them from the perspective of unique selling points already capturing intangible attributes.

The results of the workshops were summarised and distributed previous to the third and final workshop. The aim of the last workshop was to lead the three partner cities towards the development of an interpretative strategy for their own city as a cultural heritage tourist destination and to develop interpretative themes and key messages and then to evaluate how they could be applied for the city and further integrated in their own interpretative strategy. The workshop itself was structured to feed back and build on previous outcomes. 
The workshop participants then chose stories with the greatest potential in terms of interpretation and communication for cultural heritage tourism, and analysed and evaluated them regarding potential for further development using SWOT analysis and reflection on its meaning. The workshops were held in English in Amsterdam, in German in Leipzig and in Italian in Genoa to overcome language barriers. All workshop and supporting material was first produced in English, and then translated and cross-checked by representatives in the partner cities.

\section{Results}

Amsterdam's tangible heritage dominates its identification of its main attractions. Museums were on the top of the list, followed by canals (either as an attractive feature or in terms of services provided on them), the red light district, but also naming the city's architecture and its historical buildings. The intangible features identified were the city's culture and the (unspecified) mentality of its inhabitants. Key attributes combine both the appreciation of Amsterdam's intangible cultural heritage - foremost its atmosphere, but also the freedom the city provides. The more tangible attributes mentioned were the village-like compactness, and offering new and fun experiences as the city is seen as being like an open-air museum offering direct experience of its cultural heritage.

Stories being told to tourists about Amsterdam are composed of a complex amalgam of tangible and intangible aspects of the city. Prime amongst these stories is the notion of the city as a continuous settlement, as living history where places can be visited where people lived 400 years ago and still live today. But, written into these physical places, there is also the cultural history of seagoing, trading, artistic and creative people. Commerce and creativity are manifested in the form of the city and its buildings. But just as important are the intangible strands - the notion of Amsterdam as a liberal, friendly and tolerant city. The most potent strand of experiences was seen as moving to a compact historical space, on both land and water. This contains both a guided "exploration and interpretation" and an "unguided exploration". In this sense a theme of hidden treasures emerged.

In the third workshop both group of participants explored the variety of stories connecting different aspects. An attempt was made to identify unifying factors that could be used to cluster these stories for subsequent development. The two main stories explored were a "guided tour through a diverse and living history" and a "non-guided tour - build your own Golden Age, here and now".

Discussions indicate strong support towards tours, and the routing mechanisms used to underpin these, as effective vehicles for integrating the diverse range of attractions and other elements of cultural heritage that the city has to offer. They also see tours as structuring devices that can both extend the range of attractions that tourists may visit and as a potent method of adding enhanced meaning - in the form of cultural heritage interpretation - to tourists' experiences whilst they follow the routes provided.

The workshops' findings for Genoa could play an interesting role in defining an appropriate strategy for Genoa's cultural tourism, contrasting the weaknesses and threats highlighted in the SWOT analysis. The main hidden treasure discovered through the workshop is actually the sea. The paradox is that cultural tourism linked to the aquatic theme is at the same time the main attraction of the city: both the Aquarium and the Galata museum of the sea work very well in this context. But participants stressed the necessity to re-discover the sea further, as both a resource for activities on it and as a departure point to visit the historical urban centre and its "Rolli palaces", a UNESCO heritage with a unique cultural focal point. These were connected to the more immaterial elements of the city, such as its smells, classical and contemporary music, urban atmosphere and the particular pleasure of getting lost.

Overall, the sea and the "Rolli palaces" emerged as the two main stories, linking them not only in its physical space but also a re-thinking of traditional and quite hidden concepts of its particular features in relationship with the individual perception of the city. This non-guided form of tours emerged in a similar way as in Amsterdam, in contrast to guided tours. 
However, participants stressed that the experience of those stories should not only relate to the past but also include what they called "young" Genoa, the capital of innovation. It is clearly anticipated that this aims to replace the image of the city as the capital of an "old" county where Genoa is visited mainly for its climatic conditions in winter. Connecting these past and present perceptions of the city, Genoa is noticeably an example that heritage is not frozen in time, but constantly reinvented and lived in.

The main focus of Leipzig, the third partner city, was to explore opportunities for their specific cultural heritage related to the "Gründerzeit", as part of its urban regeneration using tourism as one means to commodify its physical conservation but also its new use, capturing the spirit of the past time but also the present, its conservation process. From the outset of the workshops a lack of definition of "Gründerzeit' emerged, suggesting that Leipzig has to establish a concept of "Leipziger Gründerzeit" as a buzzword by stressing its special connection with the city, the civic society and its cultural heritage. "Leipziger Gründerzeit" was described by the workshop participants as a locally specific form of rapid economic and social growth between approximately 1880 and 1918. The unique characteristics of Leipzig at this time in comparison to other German "Gründerzeit" cities was viewed from a historical perspective and relates to the Bourgeois City with its rich culture, its specific and contingent cultural heritage and association with books and book fairs.

From a modern day perspective, this still connects to the contemporary city of fairs as well as to the unique structure and form of preserved buildings, architecture and their assemblages of the different quarters. This uniqueness was highlighted as the main potential of "Gründerzeit" as a motivation to visit. Specifically, the architectural compactness and the range of different quarters reflecting both public and private elements of city life for a variety of different social classes were seen as being particularly interesting to potential visitors as well as the quality of the restoration of "Gründerzeit" buildings and quarters. The stories identified were restoration of the cultural heritage of the "Leipziger Gründerzeit", technical achievements, and the Bourgeois City. It was felt they had the most potential for being delivered in an exciting and engaging way for visitors, meaning that very careful attention should be paid to both the content and medium of any interpretation as well as ensuring that a variety of stakeholders can take part in delivering the stories at particular sites.

Telling stories was particularly interesting - connecting between the past and the present to enable visitors to make emotional and personal connections to the everyday settings of both domestic and working life in the late nineteenth and early twentieth centuries. Moves could be made to ensure the integrity of a particular definition of "Gründerzeit" mobilised as part of an interpretative strategy, especially ensuring that the term is understood to refer variously to a period of time, a material landscape and a way of life. It will be important to maintain this unity of concepts in order to avoid confusing visitors and to ensure that educational objectives are met.

\section{Conclusions}

The bottom-up approach for the interpretative strategy enabled the cities to develop a different and deeper perspective on their cultural and heritage resources. By retaining an open mind, they reflected on their cultural assets, its novel combinations, and the aspects that can be valorised for tourism purposes, city life and culture and contribute to regeneration and conservation for the benefits of residents and tourists alike. The strategy development was city-driven, focusing on their own specifications of their particular needs to fill gaps and wants of stakeholders and city communities by providing understanding of and access to their particular cultural heritage and the places and stories connected to it. Participants of all workshops in all three cities had an urge to tell these stories, felt personally connected to them and therefore pushed developments further to make the story telling of their cultural heritage happen. The integration of citizen groups as representatives of the city's communities, stakeholders and destination managers proved to be valuable and was the key to the success of the achievements of these working groups. Driven by the ISAAC project representatives of each city, the workshops enabled them to provide a platform to 
enable this integration and communication between them, which continued beyond the workshops and will continue in the future.

The three workshops guiding the cities of Amsterdam, Leipzig, and Genoa to an outline of an interpretative strategy demonstrated that, independent from their previous tourism marketing experience, each city benefited from including interpretation in their marketing efforts. Each city started with a different focal point but over time they all focused on a specific theme where they put in all their interpretation effort, independently telling hidden treasure stories of their city.

The three examples of interpretative strategies demonstrate the usefulness of such strategies for destinations on a city or regional level, working to improve competitiveness through development of a stronger, more distinctive and unique positioning strategy. Discovering their own interpretation enables communities to discover and connect with their heritage and to protect and sustain their heritage value. Furthermore, the process to develop such interpretative strategies facilitates co-operation between destination management, the destination stakeholders and local residents. Common elements of such an interpretative strategy should centre - as an attraction-based interpretative strategy would - on both intangible and tangible unique selling points of the city, its associated stories and prospectively interesting themes for visitors. This analysis of the status quo of a destination is connected to the aims and objectives of the interpretative strategy, and with the broader strategic aims of the destination, as well as with current and prospective (new) target markets. Further elements within such a strategy need to reflect on mechanisms enabling these aims and objectives to be achieved, budget and management, and also possible factors affecting the implementation.

All three cities decided independently to tell the relatively hidden treasure of their city in the form of virtual guided walks, which can be used also on site. This means these stories were taken forward to be development within the ISAAC platform supporting both the pre-visit and the during-visit periods. Cultural heritage in a city context lends itself for trail-based interpretation. Developing such interpretation is also effective in integrating communities as a means of how they want to present themselves (Goodey, 2006).

If tourism is a lifelong and career-like pursuit, individuals tend to collect sights/sites of varying degrees of uniqueness and standardisation during their life course. Leipzig and Genoa need to grasp opportunities to present themselves as both uniquely and inherently interesting cities and as one of many European cultural heritage tourist-historic cities that are integrated into more complex itineraries. Operationalising an interpretative strategy that builds upon the stories that emerge from the workshops in each of these cities is one of the ways of implementing this strategy.

Ascertaining how best to interpret and re-tell such stories in order to engage, touch and reach out to visitors before, during and after their visits is important. The intangibles of the cities' cultural heritage need to be communicated to potential visitors alongside the tangible elements of cultural heritage - these intangible feelings, emotions and spirits will enliven the material heritage.

\section{References}

Ashworth, G.J., Graham, B. and Tunbridge, J.E. (2007), Pluralising the Pasts. Heritage, Identity and Pace in Multicultural Societies, Pluto Press, London.

Black, G. (2005), The Engaging Museum: Developing Museums for Visitor Involvement, The Heritage: Care-Preservation-Management, Routledge, London.

Buhalis, D. (2000), "Marketing the competitive destination of the future", Tourism Management, Vol. 21 No. 1, pp. 97-116.

Carter, J. (2001), A Sense of Place: An Interpretative Planning Handbook, Tourism and Environment Initiative, Inverness. 
Chacko, H.E. (1997), "Positioning a tourism destination to gain a competitive edge", Asia Pacific Journal of Tourism Research, Vol. 1 No. 2, pp. 69-75.

Copeland, T. (2006), "Constructing pasts: interpreting the historic environment", in Hems, A. and Blockley, M. (Eds), Heritage Interpretation, English Heritage/Routledge, London.

Copeland, T. and Delmaire, Y. (2004), "Heritage interpretation in the framework of the European Heritage Days", Vol. 2003, Report on the Training Course 2003 for European Heritage Days Coordinators, Council of Europe, Strasbourg.

Crompton, J., Fakeye, P. and Lue, C. (1992), "Positioning the example of the lower Rio Grande Valley in the winter long stay destination market", Journal of Travel Research, Vol. 31 No. 2, pp. 20-6.

Gnoth, J. (2008), "Branding Auckland”, NZ Marketing Magazine, Vol. 27 No. 11, pp. 15-17.

Go, F.M. and Govers, R. (2000), "Integrated quality management for tourist destinations: a European perspective on achieving competitiveness", Tourism Management, Vol. 21 No. 1, p. 79.

Goodey, B. (2006), "Interpreting urban heritage", in Hems, A. and Blockley, M. (Eds), Heritage Interpretation, English Heritage/Routledge, London.

Hems, A. (2006), "Introduction: beyond the graveyard - extending audiences, enhancing understanding", in Hems, A. and Blockley, M. (Eds), Heritage Interpretation, English Heritage/Routledge, London.

Herbert, D.T. (1989), "Does interpretation help?", in Herbert, D.T., Prentice, R.P. and Thomas, C.J. (Eds), Heritage Sites: Strategies for Marketing and Development, Avebury, Aldershot.

HERIAN (2006), "Local Intepretation Plans - a toolkit to help communities explore local heritage", available at: www.herian.org/ (accessed 28 March 2008).

Heritage Council of New South Wales (2005), "Heritage Information Series: Heritage Interpretation Policy", Department of Planning, Heritage Office, New South Wales Government, available at: www. heritage.nsw.gov.au/docs/interpretationpolicy.pdf (accessed 28 March 2008).

Knox, D. (2008), "Spectacular tradition: Scottish folksong and authenticity", Annals of Tourism Research, Vol. 35 No. 1, pp. 255-73.

Kotler, P., Bowen, J.T. and Makens, J.C. (2006), Marketing for Hospitality and Tourism, 4th ed., Pearson Prentice Hall, Upper Saddle River, NJ.

Lord, B. and Dexter, G. (2002), The Manual of Museums Exhibitions, Altamira Press, Lanham, MD.

McCabe, S. (2009), Marketing Communications in Tourism and Hospitality. Concepts, Strategies and Cases, Elsevier, Oxford.

Nyapaune, G.P., White, D.D. and Budruk, M. (2006), "Motive-based tourist market segmentation: an application to Native American cultural heritage sites in Arizona, USA", Journal of Heritage Tourism, Vol. 1 No. 2, pp. 81-99.

Pike, S. (2009), "Destination brand positions of a competitive set of near-home destinations", Tourism Management, Vol. 30 No. 6, pp. 857-66.

Prentice, R. (2006), "Evocation and experiential seduction: updating choice-sets modelling", Tourism Management, Vol. 27, pp. 1153-70.

Prentice, R. and Cunnell, D. (1997), "Response to interpretative media as a basis of multivariate market segmentation for museums and heritage centres: the case example of the people's story", Edinburgh, Museum Management and Curatorship, Vol. 16 No. 3, pp. 233-56.

Prentice, R. and Duncan, L. (1994), "Market-based product development in heritage tourism", Tourism Management, Vol. 15 No. 1, pp. 27-36.

Ritchie, J. and Crouch, G. (2000), "Marketing the competitive destination: a sustainable perspective", Tourism Management, Vol. 21 No. 1, p. 1.

Sainaghi, R. (2006), "From contents to processes: versus a dynamic destination management model (DDMM)", Tourism Management, Vol. 27 No. 5, pp. 1053-63.

Scottish Museums Council (2003a), "Fact sheet: Introduction to interpretive planning for effective museum interpretation", Scottish Museums Council, Edinburgh, available at: www.scottishmuseums. org.uk/pdfs/Factsheets/Intro_to_Interpretive_Planning_Aug_2003.pdf (accessed 28 March 2008). 
Scottish Museums Council (2003b), "Guidance note: planning for effective museum interpretation. How to write an interpretative strategy", Scottish Museums Council, Edinburgh, available at: www. scottishmuseums.org.uk/pdfs/Factsheets/Interpretive_Strategy_guidance_Aug_2003.pdf (accessed 28 March 2008).

Scottish Museums Council (2003c), "Guidance note: Planning for effective museum interpretation. How to write an interpretative plan", Scottish Museums Council, Edinburgh, available at: www. scottishmuseums.org.uk/pdfs/Factsheets/Interpretive_Plan_guidance_Aug_2003.pdf (accessed 28 March 2008).

Selby, M. (2004), Understanding Urban Tourism: Image, Culture and Experience, I.B. Tauris, London.

Smith, L.J. (2006), Uses of Heritage, Routledge, London.

Tilden, F. (1957), Interpreting our Heritage, University of California Press, Berkeley, CA.

Timothy, D.J. and Boyd, S.W. (2003), Heritage Tourism, Prentice Hall, Harlow.

Tweed, C. and Sutherland, M. (2007), "Built cultural heritage and sustainable urban development", Landscape and Urban Planning, Vol. 83, pp. 62-9.

UNESCO (1979), "Concerning the Protection of the World Cultural and Natural Heritage", available at: http://whc.unesco.org/archive/convention-en.pdf.

Wang, N. (1999), "Rethinking authenticity in tourism experience", Annals of Tourism, Vol. 26 No. 2 pp. 349-70.

Woodside, A.G., Sood, S. and Miller, K.E. (2008), "When consumers and brands talk: storytelling theory and research in psychology and marketing", Psychology and Marketing, Vol. 25 No. 2, pp. 97-145.

World Trade Organization (2006), Destination Positioning and Branding, World Trade Organization, Geneva.

\section{Further reading}

Light, D. (1995), "Heritage as informal education", in Herbert, D.T. (Ed.), Heritage, Tourism and Society, Pinter Publishers, London.

Mitsche, N., Vogt, F., Knox, D., Cooper, I., Paskaleva, K., Lomardi, P. and Ciaffi, D. (2009), "Project Deliverable 4.1: Interpretative Strategies for the Cities of Amsterdam, Leipzig and Genoa", ISAAC Project (FP6-IST-2006-035130), available at: www.isaac-project.eu (accessed 25 March 2009).

\section{Corresponding author}

Nicole Mitsche can be contacted at: nicole.mitsche@sunderland.ac.uk

To purchase reprints of this article please e-mail: reprints@emeraldinsight.com Or visit our web site for further details: www.emeraldinsight.com/reprints 